\title{
A UNESCO, o patrimônio e o turismo cultural: uma abordagem inicial (1960-1980)
}

\author{
The UNESCO, the heritage and the cultural tourism: a preliminary approach
}

(1960-1980)

\author{
Valéria Fernanda Serpa Steinke ${ }^{1}$ \\ Fernando Cesar Sossai ${ }^{2}$ \\ Ilanil Coelho ${ }^{3}$
}

\begin{abstract}
Resumo: Este artigo tem como objetivo socializar resultados alcançados com 0 desenvolvimento de uma dissertação de mestrado cujas atenções recaem sobre as relações envolvendo patrimônio e turismo no âmbito da UNESCO (1960-1980). O texto encontra-se dividido em três partes. $\mathrm{Na}$ primeira, construímos um breve histórico dessa Organização, pontuando discussões sobre patrimônio que atravessaram o processo de elaboração e promulgação da Convenção para a proteção do patrimônio mundial, cultural e natural, em 1972. Em seguida, a partir da análise de fontes coletadas junto ao UNESCO Archives (Paris, França), refletimos a respeito das maneiras pelas quais a UNESCO procurou aproximar patrimônio e turismo cultural no transcurso da década de 1970. Por último, finalizamos este escrito compartilhando duas indagações que se desdobraram do cruzamento entre a bibliografia e a análise das fontes que empreendemos em nossos recentes projetos de pesquisa.
\end{abstract}

Palavras-chave: UNESCO; Patrimônio;

Turismo.

\begin{abstract}
This article aims to socialize results obtained with the development of a Master's dissertation whose attention falls on the relationships involving heritage and tourism within UNESCO (1960-1980). The text is divided into three parts. First of all, we elaborate a short history of UNESCO, underlining some discussions about heritage that crossed the process of drafting and promulgating the Convention for the Protection of World Cultural and Natural Heritage in 1972. After that, based on the analysis of several documents research at UNESCO Archives (Paris, France), we reflect on the ways in which UNESCO undertaken efforts to become closer the notions of heritage and cultural tourism in the 1970s. In conclusion, we end this article by sharing two questions elaborated through of the crossing between our bibliography and the analysis of the documents collected in our recent research projects.
\end{abstract}

Keywords: UNESCO; Heritage; Tourism.

\section{Introdução}

A proposta deste artigo é socializar alguns dos resultados alcançados com a elaboração da dissertação de mestrado intitulada $O$ patrimônio mundial como recurso turístico? Os

\footnotetext{
${ }^{1}$ Mestranda do Programa de Pós-graduação em Patrimônio Cultural e Sociedade da Universidade da Região de Joinville (UNIVILLE). Bolsista do Fundo de Apoio à Pesquisa da UNIVILLE. Integrante do grupo Cidade, Cultura e Diferença. E-mail: steinkevaleria@gmail.com

${ }^{2}$ Docente do curso de História e do PPG em Patrimônio Cultural e Sociedade da UNIVILLE. Coorientador. Email: fernandosossai@gmail.com

${ }^{3}$ Docente do curso de História e do PPG em Patrimônio Cultural e Sociedade da UNIVILLE. Coordenadora do grupo de pesquisa Cidade, Cultura e Diferença. Orientadora. E-mail: ilanilcoelho@gmail.com
} 
paradoxos da ideia de turismo na construção da Convenção para a proteção do patrimônio mundial, cultural e natural (UNESCO, 1972), desenvolvida no transcurso dos anos de 2018 e 2019 e cujo objeto de estudo são as relações entre turismo e patrimônio, no âmbito dos bastidores da Organização das Nações Unidas para a Educação, a Ciência e a Cultura $(\mathrm{UNESCO})^{4}$.

Em diferentes sociedades contemporâneas turismo e patrimônio estão intrinsecamente conectados, sobretudo em função dos desenvolvimentos tecnológicos nas áreas da comunicação e do transporte que estimularam e facilitaram a mobilidade de pessoas por diferentes territórios, ocasionando aproximações e trocas interculturais. Diversos países, em todos os continentes, vêm se esforçando para que seus bens culturais supostamente excepcionais sejam reconhecidos pela UNESCO como patrimônios mundiais e, com isso, ampliar e/ou fortalecer suas possibilidades de ganhos econômicos em torno do patrimônio (PEIXOTO, 2002). Nesse processo, o patrimônio tem sido acionado por órgãos da gestão pública não apenas como um recurso memorial ou identitário de uma determinada sociedade para ela mesma ou, ainda, para seus futuros legatários. Para além disso, o patrimônio também é vislumbrado como um ativo econômico, capaz de ser artificialmente produzido, que contribui para a dinamização de mercados turísticos cada vez mais competitivos e globalizados, uma verdadeira "indústria do turismo" (FAUCONBERG, BERTHON, BERTHON, 2017).

Contudo, ainda são pouco numerosos os estudiosos que se dedicaram a investigar em profundidade o momento em que emergiu e historicamente ganhou força uma crença difusa segundo a qual a associação entre turismo e patrimônio poderia ser um bom negócio, negócio esse que poderia ser bom, também, para a vida de "comunidades" diretamente envolvidas com o patrimônio (BENHAMOU, 2016).

Visando contribuir para essa discussão, este artigo encontra-se dividido em três partes. Na primeira, construímos um breve histórico a respeito da UNESCO, procurando indicar as discussões sobre patrimônio que atravessaram essa Organização à época da promulgação da Convenção para a proteção do patrimônio mundial, cultural e natural (1972).

Em continuidade, na segunda parte, empreendemos uma análise de conteúdo de fontes primárias que registram alguns dos movimentos realizados pela UNESCO no sentido de

\footnotetext{
${ }^{4}$ A referida Dissertação encontra-se vinculada a dois projetos de pesquisa que, desde 2016, têm sido desenvolvidos com aportes do Fundo de Apoio à Pesquisa da UNIVILLE. Quais sejam: a) "Patrimônio cultural, entre redes e enredos", sob coordenação da professora Dra. Ilanil Coelho; e "Pelos bastidores da UNESCO: a construção de consenso em torno de bens considerados patrimônios mundiais (UNESCO, 1960-1980)", coordenado pelo professor Dr. Fernando Cesar Sossai. Algumas informações sobre esses projetos podem ser consultadas em: $<$ http://houniville.wixsite.com/novo/projetos>.
} 
aproximar patrimônio e turismo durante a década de 1970. Fazendo uso de documentos coletados durante os meses de julho e agosto de 2018 no UNESCO Archives (http://www.unesco.org/archives/), situado junto à sede dessa organização, na cidade de Paris (França), refletimos sobre os esforços da Instituição para associar e difundir os termos patrimônio e turismo cultural ${ }^{5}$.

Por último, finalizamos este artigo com algumas conjecturas em torno de duas intrigantes questões que se desprenderam do cruzamento entre os estudos teórico-conceituais e a análise documental que temos empreendemos em nossos recentes projetos de pesquisa.

\section{A UNESCO e a Convenção para a proteção do patrimônio mundial, cultural e natural de} 1972

Inicialmente, a aprovação para a criação da UNESCO ocorreu durante a Conferência de Londres, no ano de 1945, em um contexto em que se discutia formas de construção da paz internacional em mundo pós Segunda Guerra Mundial. Todavia, a constituição oficial da Organização deu-se apenas no ano seguinte, em novembro de 1946, como um corpo institucional vinculado à Organização das Nações Unidas - ONU (SOSSAI, 2017).

Em função dos destroços e graves danos causados aos bens culturais durante as duas Grandes Guerras que transcorreram durante a primeira metade do século XX, debateu-se, no interior da UNESCO, a necessidade de se criar e instaurar internacionalmente regimentos e políticas voltadas à preservação de monumentos e sítios patrimoniais situados em diferentes partes do Globo.

Na esteira desses debates, foi promulgada, em 1954, a "Convenção e o protocolo para a proteção de bens culturais em caso de conflito armado", popularmente conhecida como Convenção de Haia (UNESCO, 1954). À época, tratou-se do primeiro tratado internacional multilateral a possuir uma agenda focada na proteção do patrimônio localizado em zonas de conflitos armados. Em linhas gerais, as diretrizes de tal documento enfocavam a proteção de bens sob responsabilidade e custódia dos seus respectivos Estados, bem como fixavam as disposições jurídicas relacionadas à gestão de bens culturais.

\footnotetext{
5 A pesquisa no UNESCO Archives resultou na digitalização de, aproximadamente, quatro mil páginas de documentos (atas de reunião, memorandos internos, cartas, rascunhos de documentos oficiais, boletins, orçamentos e programas de trabalho da Organização, entre outros). Neste artigo, os documentos que citamos foram analisados por meio de uma Ficha de Análise especificamente elaborada para tal. Ademais, vale a pena registrar que os excertos documentais que inserimos neste escrito foram originalmente elaborados em língua inglesa e traduzidos por nós ao português do Brasil.
} 
Ainda que a Convenção de Haia tenha sido um documento capital para os debates acerca dos modos de gestão e proteção de bens culturais considerados internacionalmente relevantes, foi apenas durante a $17^{\mathrm{a}}$ Sessão da Conferência Geral da UNESCO, realizada em Paris, entre 17 de outubro e 21 de novembro de 1972, que foi elaborada a "Convenção para a proteção do patrimônio mundial, cultural e natural", e, também, instaurou-se o "Comitê de Patrimônio Mundial", órgão voltado à gestão de políticas patrimoniais criadas e globalmente disseminadas pela Organização (UNESCO, 1972). Em outras palavras, tal Convenção, em tese, definia, normatizava e estabelecia parâmetros e diretrizes sobre o que poderia ser definido como patrimônio mundial, cultural e natural, com o objetivo norteador de permitir que as nações cooperassem na proteção dos sítios culturais e naturais de valor excepcional para a humanidade.

Segundo a própria UNESCO, em 1972, a Convenção para a proteção do patrimônio mundial, cultural e natural

[...] adotou a premissa de que certos sítios têm extraordinário valor universal e, desta forma, são parte do patrimônio comum da humanidade. Embora respeitando plenamente a soberania nacional, e sem prejuízo dos direitos de propriedade previstos pela legislação nacional, os Estados-Partes da Convenção reconhecem que proteger o Patrimônio Mundial é dever da comunidade internacional como um todo (UNESCO, 2007, p. 17).

De acordo com Cameron e Rössler (2013), à época, o texto final da Convenção foi considerado pelos Estados-membros da Organização um documento icônico e que representava um consenso possível em torno da noção de "Valor Universal" de um bem cultural e/ou natural considerado patrimônio de diferentes sociedades, bem como estipulava algumas obrigações internacionais no que concerne à proteção de bens patrimonializados.

No entanto, é importante registrar que, desde o início da década de 1960, vinham sendo delineadas, por outras instituições, medidas para proteger bens internacionalmente considerados de interesse patrimonial (culturais e/ou naturais). Segundo Cameron e Rössler (2013), três principais instituições foram pioneiras na construção de uma política protecionista patrimonial, a saber, a União Internacional para a Conservação da Natureza (IUCN), com ênfase no patrimônio natural; a UNESCO, com maior destaque ao patrimônio cultural (monumentos, construções e sítios históricos e arqueológicos); e o governo dos Estados Unidos da América (EUA).

Cada um desses órgãos apresentou, em setembro de 1971, em Nova Iorque, ao Grupo de Trabalho Intergovernamental sobre Conservação (IWGC), da UNESCO, uma minuta da 
Convenção para a proteção do patrimônio mundial, em preparação à Conferência de Estocolmo ${ }^{6}$ que viria a ocorrer em meados de 1972. No encontro de Nova Iorque, foi sugerido à IUCN, à UNESCO e aos representantes do governo dos EUA que elaborassem um novo documento em que fosse fundido as três minutas apresentadas. A UNESCO assumiu a liderança dessa tarefa, constituindo uma equipe de experts para dar redação às principais disposições da Convenção de 1972.

Na esteira desse cenário, seis anos após a Convenção de 1972, foram oficialmente nomeados pela UNESCO os primeiros bens considerados como patrimônios mundiais. No total, doze bens culturais e/ou naturais foram anunciados como patrimônios mundiais em 1978 (oito foram considerados patrimônios mundiais culturais e quatro definidos como patrimônios mundiais naturais ${ }^{7}$ ).

Nas décadas subsequentes, sobretudo após a queda do Muro de Berlim (1989), ganhou espaço em diferentes sociedades do mundo ocidental - em especial nos países europeus - um intenso processo de patrimonialização de bens culturais (HARTOG, 2006). Na esteira dessa inflação patrimonial, evidenciou-se um crescimento considerável no número de inscrições junto à UNESCO de bens candidatos à patrimônio mundial, notando-se um movimento de expansão e de difusão global da noção de patrimônio agenciada pela Instituição, como atesta o sociólogo português Paulo Peixoto:

A classificação como patrimônio mundial, atribuída anualmente pela UNESCO desde 1978, permite demonstrar que a última década do século XX fica marcada, ao nível das políticas urbanas, por uma clara intensificação dos processos de patrimonialização e por uma corrida a esse status da UNESCO. Esse fenômeno é particularmente visível em Portugal e, de um modo mais amplo, na Europa, onde adquire contornos de uma competição entre concorrentes profissionais (PEIXOTO, 2002, p. 23).

Tendo em mente as informações apresentadas neste item, a seguir, passamos a uma discussão sobre os modos de aproximação entre patrimônio e turismo empreendida pela UNESCO durante a década de 1970. Em especial, nossas atenções recaem sobre como a Instituição se movimentou para associar, promover e difundir junto aos seus Estados-membro

\footnotetext{
${ }^{6}$ Conferência das Nações Unidas sobre o Meio Ambiente Humano. Foi a primeira grande reunião de líderes mundiais a respeito da importância da preservação do meio ambiente.

${ }^{7}$ Os doze primeiros bens tidos como patrimônios mundiais foram: a) Patrimônios mundiais culturais: a Catedral de Aachen, na Alemanha; a cidade de Quito, no Equador; o Centro Histórico de Cracóvia, na Polônia; a Ilha de Gorée, no Senegal; o Sítio Histórico Nacional de L'anse aux Meadows, no Canadá; o Parque Nacional Mesa Verde, nos Estados Unidos; as Igrejas Escavadas na Rocha, na Lalibela, Etiópia; as Minas de Sal Real de Wieliczka e Bochnia, na Polônia. Patrimônios mundiais naturais: a Ilha de Galápagos, no Equador; o Parque Nacional Nahanni, no Canadá; o Parque Nacional Simien, na Etiópia; e o Parque Nacional Yellowstone, nos Estados Unidos.
} 
a noção de turismo cultural por meio do uso de bens culturais e/ou naturais considerados patrimônios.

\section{Patrimônio e turismo cultural no interior da UNESCO}

Tentando compreender como a UNESCO historicamente aproximou os termos patrimônio e turismo, durante os meses de julho e agosto de 2018, realizamos uma coleta documental junto ao UNESCO Archives, na sede da UNESCO (Paris). A análise de conteúdo da documentação que coletamos revela que, no transcurso das décadas de 1960 e 1970, a Organização envidou esforços em torno da associação entre patrimônio e o então denominado “turismo cultural”. No Relatório do ano de 1968, elaborado pelo Diretor Geral da UNESCO em 1969, vemos claramente um encorajamento do turismo cultural por parte da Organização nos anos anteriores à promulgação daquela Convenção de 1972.

Durante sua $14^{\mathrm{a}}$ Sessão, a Conferência Geral discutiu formas e meios pelos quais a UNESCO poderia contribuir mais efetivamente para $o$ desenvolvimento da década. A Instituição aprovou uma resolução [...] em que, entre outros, sugeriu-se implantar medidas para encorajar o turismo cultural (UNESCO, Atividades da Organização, 1969, p. 114-115, tradução nossa).

Outra documentação pertinente a nossas discussões é o Relatório do ano de 1972, elaborado sob os auspícios do Secretário Geral da UNESCO. Tal Relatório traz informações significativas no que tange às supostas vantagens que a promoção do turismo cultural em larga escala poderia assegurar aos Estados-membros da Instituição:

Nos últimos 6 ou 8 anos, a Organização tem feito um trabalho útil na promoção da preservação e apresentação do patrimônio cultural para grandes públicos, usando o conceito ou o mecanismo do "turismo cultural". A relevância do "turismo cultural" será reforçada [...] para nações em desenvolvimento ou para agências de financiamento internacionais proporcionarem verbas para a preservação e difusão de seus monumentos [...]; mata-se dois pássaros com uma única pedra: ele [o turismo cultural] preserva e torna viável, tanto para a presente geração como para a posteridade, importantes elementos do patrimônio cultural da humanidade, e, através disso, tem-se, também, incremento do crescimento econômico (UNESCO, 1973, p. 145, tradução nossa).

Nessa fala do Secretário Geral da Instituição podemos inferir que a promoção turismo cultural associada ao patrimônio era incentivada pela UNESCO há seis ou oito anos, ou seja, já por volta dos anos 1964 ou 1966. 
Para além disso, no conjunto dos documentos pesquisados na sede da UNESCO, percebemos que até o ano de 1974, via de regra, a relação entre turismo e patrimônio é repetidamente vislumbrada como benéfica para todos (Estados, UNESCO, empresários, comunidades residentes nas imediações de bens patrimonializados, entre outros). Porém, no documento relativo ao Programa e Orçamento Aprovados para o Biênio de 1975 e 1976, promulgado durante a $18^{\mathrm{a}}$ Sessão da Conferência Geral da UNESCO, registrou-se alguns possíveis malefícios da relação entre patrimônio e turismo cultural:

Os efeitos do turismo sobre os valores socioculturais: o desenvolvimento do turismo cultural tem permitido aos Estados-membros financiarem a conservação e preservação de certos monumentos e sítios. Mas, quando o fluxo de turistas excede um certo limite, isso pode ter consequências em âmbito sociocultural, causando mudanças que podem ameaçar os valores culturais. Assim, será realizado um estudo interdisciplinar sobre o desenvolvimento do turismo e sobre a preservação de valores culturais tradicionais [...] (UNESCO, 1975, p. 326, tradução nossa).

Nota-se uma preocupação com os possíveis efeitos decorrentes da intensificação do turismo cultural por meio de usos do patrimônio. Ao que tudo indica, entre os gestores da UNESCO, pairava certo temor de que a massificação do turismo cultural pudesse gerar um problema de difícil de mediação: a perda de supostos valores socioculturais tradicionais de sociedades que, historicamente, produziram e mantiveram bens culturais que até então lhes eram próprios.

Igualmente, órgãos vinculados à UNESCO bastante especializados na discussão sobre patrimônio também nutriam desconfiança em relação à aproximação entre turismo cultural e patrimônio. Por exemplo, em 1976, o Conselho Internacional de Monumentos e Sítios (ICOMOS ) - órgão com participação direta na escolha de bens candidatos a integrar a Lista de Patrimônio Mundial da Organização -, elaborou a Carta de Turismo Cultural. Em tal documento, o ICOMOS registrou de maneira muito clara suas ressalvas a respeito do enlace entre turismo cultural e patrimônio:

O Turismo Cultural é aquela forma de turismo que tem por objetivo, entre outros fins, o conhecimento de monumentos e sítios histórico-artísticos. Exerce um efeito realmente positivo sobre estes tanto quanto contribui - para satisfazer seus próprios fins - a sua manutenção e proteção. Essa forma de turismo, justifica, de fato, os esforços que tal manutenção e proteção exigem da comunidade humana, devido aos benefícios socioculturais e econômicos que comporta para toda a população implicada. Sem dúvida, qualquer que seja sua motivação e os benefícios que possui, o turismo cultural não pode estar desligado dos efeitos negativos, nocivos e destrutivos que acarreta o uso 
massivo e descontrolado dos monumentos e dos sítios (ICOMOS, Carta de Turismo Cultural, 1976, p. 2).

De acordo com o ICOMOS, na relação entre patrimônio e turismo cultural, era imperativo evitar a coisificação do patrimônio, em especial evitar o equívoco de reduzir o patrimônio a mero artefato turístico destinado a um consumo, por vezes, predatório ou destrutivo.

Em que pesem as advertências do ICOMOS, assim como de alguns gestores que atuaram durante os anos 1970 junto à UNESCO, na contemporaneidade, não é raro nos depararmos com casos em que bens patrimoniais são gerenciados por governos ou empresários como um "recurso econômico", altamente rentável e, imaginariamente, renovável a partir de investimentos que resultam em novas formas de apresenta-lo para consumo. Respondendo às expectativas do "turismo de massa", sem dúvida, estamos numa era em que o patrimônio é convertido e empacotado como um "produto do mercado" (SMITH, 2006, p. 33, tradução nossa).

De nossa perspectiva, não significa advogar contra todo e qualquer uso turístico do patrimônio. Tampouco, acreditamos que todo e qualquer uso econômico do patrimônio é nocivo. Apenas reforçamos a necessidade de analisarmos de maneira mais aprofundada a "natureza desse relacionamento". Não podemos deixar de considerar que o turismo, se bem pensado e desenvolvido, pode ser "uma alternativa valiosa para a conservação do patrimônio", enfrentando certas formas e "atividades de desenvolvimento econômico" que poderiam "significar a destruição" de bens patrimoniais (HALL, 2001, p. 3, tradução nossa). Ao que nos parece, é fundamental uma postura academicamente arguta frente a esse tipo de discussão.

\section{Considerações finais}

Nossa investigação a respeito do relacionamento entre patrimônio e turismo no processo de construção da Convenção para a proteção do patrimônio mundial, cultural e natural (UNESCO, 1972), ainda continua em andamento. Em sua etapa atual, pretendemos aprofundar a análise de conteúdo da documentação recolhida, in loco, na sede do UNESCO Archives. Esperamos que esse procedimento contribua para o melhor conhecimento dos posicionamentos e motivações históricas que levaram à UNESCO a ora defender, ora criticar, a fusão entre turismo cultural e patrimônio. 
Analisar em detalhes a história da UNESCO, em especial as relações de bastidores que transpassaram essa Instituição, é essencial para compreendermos porque certos bens patrimoniais foram reconhecidos pela Organização como bens de valor universal excepcional e, com isso, elevados ao status de patrimônios mundiais (GFELLER, 2013).

Em se tratando dos modos de escolha desses bens, é fundamental pesquisarmos como órgãos da UNESCO - muitos deles altamente especializados em discussões sobre patrimônio (Comitê do Patrimônio Mundial, ICOMOS, entre outros) -, grupos de experts e representantes de governos foram envolvidos em processos de tomada de decisão que, entre outros, resultaram na produção e disseminação internacional de documentos que parecem ter inaugurado uma espécie de "política global" de gestão e proteção do patrimônio. Isso talvez contribua para lançarmos algumas luzes sobre o papel ora estratégico, ora tático, da UNESCO na "modelagem do patrimônio mundial" (GFELLER e EISENBERG, 2016, p. 279).

Nessa direção, por meio da pesquisa histórica, talvez seja possível a produção de algumas respostas para duas intrigantes questões que emergiram do cruzamento entre os estudos teórico-conceituais e as análises documentais que realizamos em nossas recentes pesquisas: no âmbito de atuação da UNESCO, em que medida o patrimônio foi historicamente e intencionalmente acionado como um recurso econômico para animar o turismo? O turismo foi um recurso para ampliação das políticas de patrimônio dessa Organização?

Esperamos que este artigo seja uma contribuição relevantes para reflexões que rumam nessa direção.

\section{Referências bibliográficas}

BENHAMOU, Françoise. Economia do patrimônio cultural. Tradução de Fernando Kolleritz. São Paulo: Edições SESC, 2016.

CAMERON, Christina; RÖSSLER, Mechtild. Many Voices, one vision: the early years of the World Heritage Convention. New York: Routledge, 2013.

FAUCONBERG, Ariel de; BERTHON, Pierre; BERTHON, Jean Paul. Rethinking the marketing of World Heritage Sites: Giving the past a sustainable future. Journal of public affairs, v. 18, n. 2, p. 1-7, 20 mar. 2017.

GFELLER, Aurélie Élisa. Negotiating the meaning of global heritage: "cultural landscapes" in the UNESCO World Heritage Convention, 1972-92. Journal of global history, 8, p. 483-503, 2013.

GFELLER, Aurélie Élisa; EISENBERG, Jaci. UNESCO and the shaping of global heritage. In: DUEDAHL, Poul. A History of UNESCO. London: Palgrave Macmillan, 2016. p. 279-324. 
HALL, C. M. World Heritage and Tourism. Tourism Recreation Research, v. 26, n. 1, p.1-3, jan. 2001.

HARTOG, François. Tempo e Patrimônio. Revista Varia História, v. 22, n. 36, p. 261-273, $\mathrm{jul} / \mathrm{dez}, 2006$.

KAJZAR, Patrik. Cultural tourism and World Heritage. In: 17th International Colloquium on Regional Sciences. Hustopeče, 2014. p. 901-906.

ICOMOS. Carta de Turismo Cultural. Paris, nov.1976.

PEIXOTO, Paulo. A corrida ao status de patrimônio mundial e o mercado urbano de lazer e turismo. Veredas revista científica de turismo, v. 1, n. 1, p. 23-45, jul. 2002.

SMITH, Laurajane. Uses of heritage. New York: Routledge, 2006.

SOSSAI, Fernando Cesar. Pelos Gabinetes da OCDE: a construção de consensos sobre educação e tecnologia (1960-1992). Tese. 272 f. Programa de Pós-graduação em Educação. Universidade do Estado de Santa Catarina (UDESC). Florianópolis-SC, 2017.

UNESCO. Approved Programme and Budget for 1975-1976. General Conference: $18^{\text {th }}$ Session. Paris, 1975.

UNESCO. Convenção para a proteção de bens culturais em caso de conflito armado. Haia, 14 mai. 1954.

UNESCO. Convenção para a proteção do patrimônio mundial, cultural e natural. Paris, 1972.

UNESCO. Draft programme and budget for 1973-1974. Paris, 1973.

UNESCO. General Conference: first session. Paris, 1947.

UNESCO. O que é? O que faz? Paris, 2007.

UNESCO. Report of director general on the activities of the Organization in 1968. Paris, 1969.

UNESCO. Report of director general on the activities of the Organization in 1972. Paris, 1973. 